\title{
Primeiro centenário do Tribunal de Justiça do Estado de São Paulo.
}

\author{
Flávio Galvão * \\ Bacharel pela Faculdade de Direito da Uni- \\ versidade de São Paulo; jornalista; profes- \\ sor contratado da Escola de Comunicações \\ e Artes da USP.
}

"Aos 3 dias do mês de fevereiro do ano do nascimento de Nosso Senhor Jesus Cristo de 1874, nesta Imperial cidade de São Paulo, na casa destinada para os trabalhos da Relação da mesma cidade, presentes os senhores Desembargadores Excelentíssimo Conselheiro Tristão de Alencar Araripe, Presidente da mesma Relação, João José de Andrade Pinto, Procurador da Coroa e Promotor de Justiça, José Norberto dos Santos, Frederico Augusto Xavier de Brito, Olegário Herculano de Aquino e Castro, Antônio de Cerqueira Lima e Agostinho Luís da Gama, comigo Secretário abaixo assinado, aí, pelas 11 horas da manhã, depois da benção do edifício, praticadas as solenidades religiosas pelo Reverendíssimo Monsenhor Arcediago Dr. Joaquim Manuel Gonçalves de Andrade, compareceu o Excelentíssimo Senhor Presidente $\mathrm{da}$ Província, dr. João Teodoro Xavier, o qual foi recebido à porta do salão das conferências do Tribunal por uma comissão composta dos dois mais modernos Desembargadores e de mim Secretário e dirigindo-se todos à mesa colocada no mesmo salão, o Exmo. Conselheiro Presidente da Relação deu assento na cabeceira da dita mesa em cadeira de espaldar ao mesmo Excelentíssimo Senhor Presidente da Província e ocupou a sua sede à mesma cabeceira da mesa, sentando-se os demais Senhores Desembargadores nas suas sedes conforme a ordem de suas antiguidades.

"Em seguida, estando ocupado o recinto do salão pelas dignidades eclesiásticas, Deputados Provinciais, Lentes da Faculdade, Juizes de pri- 
meira instância, e outras autoridades, Chefe de Polícia, Advogados e mais pessoas gradas devidamente convidadas, assim como por numeroso concurso de cidadãos, o Excelentíssimo Senhor Conselheiro Presidente da Relação mandou proceder à leitura dos Decretos Imperiais de nomeação e remoção dos ministros deste Tribunal e proferiu um discurso análogo a esta solenidade, findo o qual disse - Está instalada a Relação.

"Imediatamente prestou juramento o Senhor Desembargador Agostinho Luís da Gama, pondo a mão direita sobre o livro dos Santos Evangelhos e pronunciando a seguinte fórmula: "Juro servir bem e fielmente o cargo de Desembargador, mantendo a Constituição e mais leis do Império, administrando justiça com boa e sã consciência. Assim Deus me ajude"

"Não prestaram juramento os demais membros do Tribunal por já o haverem feito como Desembargadores das Relações a que pertenciam, em conseqüência do que o Excelentíssimo Senhor Conselheiro Presidente da Relação declarou todos os membros do Tribunal empossados de seus cargos, e no exercício de suas funções. E por que de nenhum outro objeto se houvesse de tratar, nem houvesse causa alguma judiciária a decidir, deu o Excelentíssimo Senhor Conselheiro Presidente o ato por findo e acabado, e mandou lavrar esta ata, declarando que na próxima sexta-feira, às 10 horas da manhã, teria lugar a primeira conferência ordinária do Tribunal.

"Para constar, eu, Bacharel João Batista de Moraes, Secretário da Relação, lavrei esta ata na qual comigo assinam os membros do Tribunal e pessoas gradas presentes ao ato".

Melhor informação não pode haver do que o documento acima transcrito sobre a instalação, a 3 de fevereiro de 1874 - um século atrás - da Relação de São Paulo, denominação antiga dos Tribunais de segunda instância no Brasil, efeméride este ano celebrada, solemente, pelo Tribunal de Justiça do Estado de São Paulo.

O primeiro signatário da ata foi o presidente da Relação, seguindose as assinaturas do presidente da província e dos ministros. Das pessoas gradas presentes ao ato, firmaram ainda ata: o presidente da Câmara Municipal, Ernesto Mariano de Souza Ramos, Antônio José Ferreira Braga, Cláudio José Pereira, José Homem Guedes Portilho, Bento J Alves Pereira, Francisco Antônio de Souza Queiroz, Martim Francisco Ribeiro de Andrada, o chefe de polícia Joaquim José do Amaral, o juiz 
de Direito Antônio Cândido da Rocha, Sebastião José Pereira, Francisco de Paula Rabelo e Silva, B. Gavião, Barão de Atibaia, Barão de Tres Rios, advogado João Ālvares de Siqueira Bueno, Barão de Itapetininga, dr. Clemente Falcão de Souza Filho, Luís Soares Viegas, Gabriel Marques Cantinho, Leôncio de Carvalho, Francisco Rodrigues Soares, Paulo Delfino da Fonseca, José Joaquim Cardoso de Melo, dr. Antônio Pinheiro de Ulhoa Cintra, dr. Luis Lopes Batista dos Anjos, José Antônio de Magalhães Castro Sobrinho, Paulo Egídio de Oliveira Carvalho, Antônio R. Veloso Pimenta, Manoel Roiz Jordão, Joaquim Pereira de Castro Vasconcelos, José Inocêncio de Moraes Vieira, João Macedo Pimentel, Ernesto Pereira Possolo, João Antônio de Oliveira Campos, Alfredo da Rocha, João Baptista de Moraes, Antônio de Araujo Freitas e Jerônimo José de Andrade.

Decreto de criação.

Foi a Relação de São Paulo criada pelo decreto n. ${ }^{\circ}$ 2.342, de 6 de agosto de 1873, pelo qual se sancionou e se mandou executar Resolução (decreto legislativo) da Assembléia Geral. Não foi a de São Paulo a única Relação então criada, mas ao todo se criaram 7 Relações novas, elevando-se assim a 11 o número desses tribunais no Império: Relação do Pará e Amazonas, com sede em Belém; do Maranhão e Piauí, em São Luís; do Ceará e Rio Grande do Norte, em Fortaleza; de Pernambuco, Paraíba e Alagoas, em Recife; da Bahia e Sergipe, em Salvador; do Município Neutro, Rio de Janeiro e Espírito Santo, na Corte (Rio); de São Paulo e Paraná, com sede na cidade de São Paulo; do Rio Grande do Sul e Santa Catarina, em Porto Alegre; de Minas Gerais, em Ouro Preto; e de Goiás, na cidade de Goiás.

Variava o número de membros das Relações, obviamente de acordo com a importância e o desenvolvimento da região a que serviam. Contava a da Corte 17 desembargadores; as da Bahia e de Pernambuco, 11; as do Pará, Maranhão, Ceará, São Paulo, Rio Grande do Sul e Minas Gerais, 7; e Mato Grosso e Goiás, 5 Interessante observar que São Paulo figurava, então, entre as províncias colocadas em terceiro plano; situação que no decorrer de um século se transformou inteiramente, colocando-se hoje o nosso Estado como o mais desenvolvido do País, sob todos os pontos de vista. 
No distrito de sua jurisdição, eram os desembargadores incompatíveis para os cargos de senador, deputado geral e deputado provincial.

Com a rubrica do Imperador, o decreto de criação foi sancionado pelo ministro da Justiça, dr. Manuel Antônio Duarte de Azevedo, membro do $25 .^{\circ}$ Gabinete, que foi o de maior duração no regime monárquico - 7 de março de 1871 a 25 de junho de 1875 - presidido pelo Visconde do Rio Branco, que acumulava ainda a pasta da Fazenda. Neste Gabinete, Duarte de Azevedo começara como ministro da Marinha, passando a titular da Justiça em 20 de abril de 1872 .

Vale recordar, "en passant", que Duarte de Azevedo, fluminense de Itaboraí, bacharel em direito por São Paulo, turma de 1856, e doutor, por defesa de tese em 1859, foi um dos luminares do Direito em sua época. Professor da Faculdade de Direito de São Paulo, na qual chegou a catedrático de Direito Romano, militou na política, tendo sido presidente das Províncias do Piauí, Alagoas e Ceará, deputado provincial, deputado geral e ministro. Faleceu no Rio, em 9 de novembro de 1912, como presidente do Senado do Estado de São Paulo.

Ao decreto de criação seguiu-se o de n. ${ }^{\circ} 5.456$, de 5 de novembro de 1873, estabelecendo que as novas Relações de Porto Alegre, São Paulo, Ouro Preto, Fortaleza e Belém começariam a funcionar no dia 3 de fevereiro de 1874 , e as de Goiás e Cuiabá, no dia $10^{\circ}$ de maio daquele mesmo ano.

Pelo decreto n. ${ }^{\circ} 5.457$, de 6 de novembro de 1873, tomaram-se providências sobre o número, as funções e os vencimentos dos funcionários das Relações.

E pelo decreto n. 5458 , também de novembro de 1873, declararam-se especiais as comarcas sedes das Relações criadas pelo decreto legislativo n. ${ }^{\circ} 2.342$ e deram-se outras providências.

\section{Retrospecto .}

O primeiro Tribunal da Relação no Brasil fora criado na Bahia, em 1587, com regimento de 25 de setembro do mesmo ano. Chegaram a ser nomeados os dez ministros que o comporiam: o chanceler os desembargadores do agravo, o ouvidor geral, o juiz dos feitos, provedor dos órgãos e resíduos, o provedor dos feitos, o promotor de justiça e os desembargadores extravagantes. Dos nomeados, alguns chegaram até a embar- 
car com Francisco Giraldes, nomeado governador geral do Brasil, mas aqui não chegaram, desistindo da viagem depois de duas arribadas do navio.

Assim, são se efetivou a instalação da primeira Relação baiana.

A segunda Relação foi criada em 1609, com regimento de 7 de março e dez desembargadores, e suprimida em 5 de abril de 1626, em consequiência da ocupação da Bahia pelos holandeses.

Foi ela restaurada por lei de 12 de setembro de 1652, com oito desembargadores, para que se administrasse e fizesse justiça igualmente aos brasileiros, livrando-os das moléstias, vexações e perigos do mar, a que estavam expostos pelo fato de irem bater às portas dos tribunais lusitanos.

Por alvará de 13 de outubro de 1751, o Brasil ganhou outro Tribunal da Relação, com sede na cidade de São Sebastião do Rio de Janeiro.

A de Salvador tinha jurisdição sobre as Capitanias da Bahia, Sergipe, Pernambuco, Paraíba, Rio Grande do Norte, Ceará, Piauí, Maranhão, Pará e Rio Negro, e a do Rio, sobre as 13 seguintes comarcas: Rio de Janeiro, São Paulo, Ouro Preto, Rio das Mortes, Sabará, Rio das Velhas, Serro Frio, Cuiabá, Goiás, Paranaguá, Espírito Santo, Goitacazes, ilha de Santa Catarina e todas as judicaturas, ouvidorias e capitanias que se houverem criado ou de novo se criassem no referido âmbito.

Emancipado o País em 1822, a Constituição Política do Império do Brasil, outorgada por D. PEDRo I em 25 de março de 1824, na parte relativa ao Poder Judiciário estabeleceu que, na Capital do Império, haveria uma Relação, assim como nas demais províncias, além de um Supremo Tribunal de Justiça .

As Relações do Império tiveram regulamento, dado por decreto de 3 de janeiro de 1833, expedido em nome de D. Pedro II, pela Regência - então integrada por Francisco de Lima e Silva, José da Costa Carvalho e João Bráulio Muniz - e referenciado por Honório Hermeto Carneiro Leão (mais tarde Visconde e depois Marquês do Paraná, ministro da Justiça do $3 .^{\circ}$ gabinete ministerial da Regência Permanente Trina)

Nesse regulamento estabeleceu-se a competência das Relações. Sofreu o regulamento modificações, por decreto de 23 de junho de 1834, entre as quais se autorizou, para facilitar o andamento dos processos, a divisão do Tribunal em duas Seç̧ões. 


\section{A $1 .^{a}$ Relação de São Paulo.}

O conselheiro Tristão de Alencar Araripe, conforme termo lavrado no livro de compromisso e posse dos desembargadores, não prestou juramente no ato da instalação da Relação paulista porque o fizera, como seu presidente, em 13 de janeiro de 1874, em mãos do Exmo. Sr. Presidente da Província.

Alencar Araripe não era paulista. Nascera em Icó, Província do Ceará, em 7 de dezembro de 1821, tendo recebido o grau de bacharel a 4 de novembro de 1845, na Faculdade de Direito de São Paulo. Segundo Spencer Vampré em sua história da Academia, Alencar Araripe nesta se matriculara em 1841, ano do falecimento de Julio Frank, o fundador de célebre sociedade secreta, nucleada na escola do Largo de São Francisco e cujos membros tiveram grande influência na vida pública do País. Em posição contrária há quem afirme que o presidente da primeira Relação paulista iniciou seu curso de direito em Olinda.

Como magistrado, Alencar Araripe começou como juiz municipal e de órfãos de Fortaleza e Áquiraz, na sua província natal, em 1847. Foi desembargador das Relações da Bahia e da Corte, vindo transferido para São Paulo, onde pouco permaneceu, sendo removido em maio mesmo de 1874 , de novo para a Corte.

Em 1886, foi nomeado ministro do Supremo Tribunal de Justiça do Império e, em 1890, já na República, foi aproveitado na primeira organização do Supremo Tribunal Federal.

Alencar Araripe faleceu no Rio, a 3 de julho de 1908.

O conselheiro Olegário Herculano de Aquino e Castro, paulista de São Bernardo, nasceu a 10 de março de 1828, bacharelando-se em 1848, na Faculdade de São Paulo, onde se doutorou em Direito no ano seguinte.

Magistrado de carreira, foi juiz nas Províncias de São Paulo, Goiás, Minas Gerais e na Corte, a cuja Relação chegou. Foi presidente da Relação paulista, ministro do Supremo Tribunal de Justiça e nomeado, em 1890, para o Supremo Tribunal Federal, de que foi eleito presidente em 1894.

Exerceu a Presidência da Província de Minas e foi chefe de polícia das de Goiás e São Paulo, nesta última por duas vezes. Por São Paulo foi ainda deputado à Assembléia Geral Legislativa . 
Faleceu no Rio, a 10 de agosto de 1906.

O desembargador Frederico Augusto Xavier de Brito era natural da Província do Rio de Janeiro, tendo-se bacharelado em São Paulo, turma de 1835.

Magistrado de carreira, foi juiz de direito nesta cidade de São Paulo e serviu na Relação de São Luís, Maranhão, de onde foi transferido para a da Corte e, depois para a de São Paulo, ao criar-se esta. Não permaneceu, também, por muito tempo em São Paulo e ainda em 1874 era de novo transferido para o Rio.

O desembargador Antônio de Cerqueira Lima era filho de um conselheiro, ministro do Supremo Tribunal de Justiça, falecido na Bahia. $\mathrm{Na}$ lista de antiguidade dos juizes de direito do Império - antiguidade contada até 31 de dezembro e 1871 - figurava ele como juiz da comarca de Inhambupe, Província da Bahia. Na lista de antiguidade dos desembargadores do Império, contada até 31 de dezembro de 1872, constava seu nome como funcionário na Relação de São Luis, sem ter até aquela data assumido o exercício. Para a Relação paulista foi nomeado por decreto de 6 de novembro de 1873 .

O desembargador Agostinho Luís da Gama também não era paulista, tendo nascido na Província de Mato Grosso. Graduou-se pela Faculdade de Direito de São Paulo, turma de 1848. No mesmo ano da formatura, foi escolhido, pela Câmara Municipal paulistana, para servir como $5 .^{\circ}$ juiz municipal suplente. Fez carreira na magistratura, tendo oficiado na Província de São Paulo e na Corte.

Sobre o desembargador José Norberto dos Santos poucos são os elementos informativos disponíveis. Magistrado de carreira, como os demais colegas da primeira Relação paulista, acredita-se que nela se deve ter iniciado em 1854, pois na lista de antiguidade dos juizes de direito do Império, organizada a 31 de dezembro de 1870 e anexa ao relatório apresentada à $3 .^{\mathrm{a}}$ sessão da $14 .^{\mathrm{a}}$ legislatura da Assembléia Geral, pelo ministro da Justiça, conselheiro Francisco de Paula Negreiros Sayão Lobato, seu nome consta como juiz de direito de Cantagalo, Província do Rio de Janeiro, com 16 anos e pouco de serviço. Na lista de desembargadores do Império, apresentada em princípios de 1873, figura como titular da Relação do Maranhão, servindo, porém, na Bahia, de onde foi removido para a Côrte, em junho de 1871 . 
Em São Paulo pouco permaneceu, retornando à Relação onde servia por decreto de 18 de fevereiro de 1875 .

O desembargador João José de Andrade Pinto nasceu no Rio de Janeiro, a 21 de junho de 1825, bacharelando-se em São Paulo no ano de 1846.

Foi juiz de direito na sua Província natal e nas de Santa Catarina e São Paulo. Desembargador da Relação da Bahia, dali foi removido para a da Côrte e, logo em seguida, para a de São Paulo.

Retornou à Relação da Côrte em 1875 e terminou sua carreira no Supremo Tribunal de Justiça falecendo no Rio, a 22 de dezembro de 1898.

Estes foram os 7 desembargadores que constituiram o Tribunal cujo primeiro centenário este ano se comemorou, em São Paulo. Deles, apenas 1 era paulista, os demais naturais de outras províncias, a maioria fluminense. Dos 7, cinco bacharelaram-se na Faculdade de São Paulo, quatro deles tendo sido contemporâneos de bancos acadêmicos e dois da mesma turma (1848). E o único paulista chegou a presidente do Supremo Tribunal Federal, nos primeiros anos da República.

\section{República .}

Com a implantação da República no País, o Estado de São Paulo teve sua primeira constituição em 1891 e organizado o seu Poder Judiciário pela lei $n .{ }^{\circ} 18$, de 21 de novembro daquele ano. Nos termos desta, era o Poder Judiciário exercido pelos Juizes de Paz, nos distritos; Juizes de Paz Adjuntos, Tribunais Correcionais e Juri, nos termos; Juizes de Direito, nas comarcas; e Tribunal de Justiça, em todo o Estado.

Assim, o Tribunal de Justiça era o órgão de cúpula do Judiciário no âmbito estadual, composto de ministros nomeados pelo governo, mediante aprovação do Senado estadual, e escolhidos dentre os juízes de direito mais antigos do Estado, apresentados em lista organizada pelo próprio Tribunal.

Por ato de 24 de novembro de 1891, o governo procedeu à nomeação dos ministros que deveriam compor o Tribunal, tendo sido escolhidos: João Augusto de Pádua Fleury, Raimundo Furtado de Albuquerque Cavalcanti, Américo Vespúcio Pinheiro e Prado, José Ignácio Gomes 
Guimarães, Agostinho Ermelino de Leão, José Maria do Vale, Frederico Dabney de Avelar Brotero, Virgílio de Siqueira Cardoso e Ignácio José de Oliveira Arruda.

Em sessão solene realizada na sede da extinta Relação do Distrito, instalou-se o Tribunal de Justiça do Estado, presentes os desembargadores da mesma Relação, João Augusto de Pádua Fleury, Américo Vespúcio Pinheiro e Prado, Agostinho Ermelino de Leão, Frederico Dabney de Avelar Brotero e José Maria do Vale e o juiz de direito Ignácio José de Oliveira Arruda, que apresentaram os seus títulos de nomeação de ministros da nova corte. Estavam presentes, ainda, o Procurador Geral do Estado, Pedro Antônio de Oliveira Ribeiro, o desembargador chefe de polícia e Carlos Augusto de Freitas Vilalva, representante do presidente do Estado, Américo Brasiliense.

Por legalmente impedidos, não compareceram os desembargadores Raimundo Furtado de Albuquerque Cavalcanti, conselheiro José Ignácio Gomes Guimarães e Virgílio de Siqueira Cardoso.

Eleito, assumiu a presidência Pádua Fleury, prestando compromisso imediatamente perante seu imediato, Pinheiro e Prado.

Secretariou a sessão Luís Augusto Pereira de Araujo.

Antes de dar os trabalhos por encerrados, Pádua Fleury anunciou que as sessões do Tribunal teriam lugar às terças e sextas-feiras às 10 horas da manhã.

\section{Anulação .}

Teve esse Tribunal pequena duração. Américo Brasiliense, que na crise política do início da República ficara ao lado do presidente, marechal Deodoro da Fonseca, por motivos decorrentes dessa posição veio a deixar a presidência do Estado de São Paulo em 15 de dezembro de 1891 .

Assumiu o cargo seu substituto legal, o dr José Alves de Cerqueira Cesar que, como informa Frederico de Barros Brotero, inscreveu em seu programa, como ponto primordial, a anulação de todas as nomeações relativas ao Poder Judiciário, procedidas no apagar das luzes do governo de seu antecessor 
Cerqueira Cesar, que assumiu o governo paulista a 16 de dezembro, no dia seguinte expediu o decreto $n .^{\circ} 6$, anulando os de n. ${ }^{\circ} 1$, de 30 de novembro, e n. ${ }^{\circ}$, de $1 .{ }^{\circ}$ de dezembro daquele ano, com o que se extinguiu o Tribunal de Justiça do Estado de São Paulo.

Nos "consideranda" do decreto $n .^{\circ} 6$, Cerqueira Cesar declarou que as nomeações dos ministros não tinham sido aprovadas pelo Senado estadual, como exigia a Constituição de São Paulo, "complemento indispensável à efetividade das nomeações, de que em regra, depende a regular investidura dos membros do referido Tribunal"

Foi esse decreto referendado por Herculano de Freitas.

Organização definitiva.

Dissolvido o Tribunal de Justiça constituido por Américo Brasiliense, continuou então a funcionar o antigo Tribunal da Relação.

Em 29 de janeiro de 1892 foi dissolvido o Congresso estadual e a 26 de fevereiro foram nomeados os secretários de Estado. No dia 23 de agosto do mesmo ano, Bernardino de Campos assumiu a presidência efetiva do Estado de São Paulo, com a preocupação de organizar, em definitivo, o Poder Judiciário.

Duas semanas decorridas, a 8 de setembro de 1892, foram nomeados para compor o Tribunal de Justiça do Estado os seguintes magistrados: Frederico Dabney de Avelar Brotero, José Machado Pinheiro Lima, Francisco Machado Pedrosa, Ignácio José de Oliveira Arruda, José Xavier de Toledo, Canuto José Saraiva, Pedro Antônio de Oliveira Ribeiro, Carlos Augusto de Souza Lima e Joaquim Augusto Ferreira Alves.

Dois dias depois, pelo decreto n. ${ }^{\circ} 103$, baixaram-se instruções para a instalação dos tribunais e juizos criados pela lei 18/1892 (lei de organização judiciária do Estado), marcando-se para o dia 13 de setembro a solene instalação do Tribunal de Justiça de São Paulo.

\section{Instalação .}

Efetivamente, no dia marcado, às 13 horas, na sede da antiga Relação, instalou-se o Tribunal de Justiça, presentes o presidente do Estado, 
Bernardino de Campos, o secretário da Justiça, Manuel Pessoa de Siqueira Campos, o diretor da Secretaria, Joaquim Roberto de Azevedo Marques Filho, os ministros nomeados, e o Procurador Geral do Estado, Antônio Carlos Ribeiro de Andrada Machado e Silva.

Como mais antigo dos ministros presentes, assumiu a presidência Frederico Dabney de Avelar Brotero, que, perante Bernardino de Campos, prestou compromisso: "Prometo cumprir com retidão, amor à justiça, e fidelidade à lei e às instituições vigentes, os deveres do cargo de ministro do Tribunal de Justiça"

A seguir, recebeu ele o compromisso dos demais ministros, sob a fórmula "Assim o prometo"

Depois de o presidente do Estado ter-se retirado do recinto, procedeu-se à eleição do presidente efetivo do Tribunal, por votação nominal. Carlos Augusto de Souza Lima obteve 7 votos, e Joaquim Augusto Ferreira Alves, 1 Ato contínuo, Souza Lima assumiu a presidência, tendo o ministro Canuto Saraiva lavrado o termo de compromisso que o presidente interino recebeu do efetivo.

O ministro Carlos Augusto de Souza Lima nasceu em Campinas, em 2 de janeiro de 1846, bacharelando-se na Faculdade de São Paulo, turma de 1866. Advogou em sua cidade natal, onde foi juiz municipal por algum tempo. Com a proclamação da República, foi nomeado delegado de polícia de Dois Córregos e, depois, juiz de direito de Rio Claro e Campinas. Presidiu o Tribunal de Justiça do Estado de 1892 a 1897, ano em que pediu demissão, retirando-se para uma propriedade agrícola em Dourado. Faleceu em 23 de setembro de 1900.

O motivo de seu pedido de demissão do mais alto cargo do Judiciário, no Estado, prendeu-se, segundo o historiador Aureliano Leite, aos graves sucessos passados em 7 de fevereiro de 1897, na cidade de Araraquara, e cuja responsabilidade se atribui a Campos Sales, sendo chefe de policia do Estado o desembargador José Xavier de Toledo. De se notar que, por tais fatos, também pedira demissão o juiz de direito daquela comarca, Joaquim Martins Fontes da Silva.

Dos ministros que compuseram o primeiro Tribunal, na República, além do presidente, Souza Lima, mais três eram paulistas: Frederico Dab- 
ney de Avelar Brotero, filho do celebre Conselheiro Brotero, professor da Faculdade de São Paulo na qual Frederico se diplomou em 1860; Ignácio José de Oliveira Arruda, natural de Bananal e bacharel da turma de 1865; e Canuto José Saraiva, nascido em Areias e Bacharel da turma de 1875 da escola do Largo de São Francisco.

O ministro José Machado Pinheiro Lima nasceu em Paranaguá, Paraná, formando-se em São Paulo, em 1871; José Xavier de Toledo era de Pouso Alegre, Minas Gerais, tendo-se bacharelado também em São Paulo, em 1866; Joaquim Augusto Ferreira Alves era natural do Rio de Janeiro e formado em São Paulo, em 1864; e Pedro Antônio de Oliveira Ribeiro era sergipano, representante do Tribunal paulista da Faculdade do Recife, onde se diplomara em 1871.

Eram maioria, pois, os ministros nascidos em outros Estados, situação semelhante à da antiga Relação, ao instalar-se em 1874 .

Sedes.

Neste século de existência — 1874-1974 — o Tribunal mudou várias vezes de sede. A Relação, em 1874, funcionava no prédio da rua Boa Vista, n. ${ }^{\circ}$ 20, situado em frente da atual rua 3 de Dezembro, com fundos para a rua 25 de março.

Dez anos mais tarde, instalou-se provisoriamente na rua José Bonifácio, antigo $\mathrm{n}^{\circ}$ 17, nas proximidades do Largo do Ouvidor (hoje Praça do Ouvidor Pacheco e Silva), enquanto se reformava o velho prédio da rua Boa Vista.

$\mathrm{Na}$ antiga sede voltou a funcionar em janeiro de 1887, ali ficando até 1900, quando se mudou para a rua Marechal Deodoro n. ${ }^{\circ} 8$, esquina da rua da Caixa d'Água, atual rua Barão de Paranapiacaba, onde permaneceu até 1909 .

De 1909 a 1915, instalou-se na rua José Bonifácio, antigo n. ${ }^{\circ}$ 13, donde se mudou em 1915, quando se demoliu o prédio, erguendo-se no local o Edifício Santa Cruz (n. ${ }^{\circ}$ 93), indo para a rua Brigadeiro Tobias, antigo n. ${ }^{\circ} 81$, onde ficou até dezembro de 1932, ano em que passou para Praça Clóvis Beviláqua, local de sua sede definitiva. 


\section{Nomes e Número.}

Variaram, também, ao longo dos anos, os nomes desse Tribunal: Relação, no Império; Tribunal de Justiça na Primeira República; Corte de Apelação sob a Constituição de 1934; Tribunal de Apelação, sob o Estada Novo; e Tribunal de Justiça do Estado de São Paulo, pelas Constituições Federal e Estadual de 1946.

$\mathrm{O}$ número de seus membros também variou. Por ocasião de sua instalação, compunha-se de 7 membros. Em 1892, o número elevou-se a 9 (decreto n. ${ }^{\circ} 103$, de setembro) e em 1895, a 12 (lei n. ${ }^{\circ} 338$, de 7 de agosto). Pela lei $757 / 1900$, o número subiu para 15 , determinando-se que o Tribunal fosse dividido em Câmaras: Civil e Criminal. O $16 .^{\circ}$ lugar criou-se em 1921, quando por determinação de lei maior, o Procurador Geral do Estado passou a ser escolhido dentre os membros do Tribunal.

A lei 2.222, de 13 de dezembro de 1927, que trata de organização judiciária, criou o cargo de corregedor geral da Justiça e determinou que o Tribunal se constituisse de três Câmaras, elevando-se a 18 o número de seus membros.

Pelo decreto $\mathrm{n} .^{\circ} 4.883$, de 11 de fevereiro de 1931 , criaram-se a $4 .^{\mathrm{a}}$ e $5 .^{\mathrm{a}}$ Câmaras do Tribunal.

O decreto 7.112 , de 2 de maio de 1935, elevou para 25 o número de desembargadores da Côrte de Apelação do Estado.

Pelo decreto 9.112 , de abril de 1938 , criou-se a $6 .^{\mathrm{a}}$ Câmara, com a denominação Criminal.

Em 21 de fevereiro de 1947, o decreto-lei n. ${ }^{\circ}$ 16.949, dispôs sobre a criação da $5 .^{\mathrm{a}}$ e $6 .^{\mathrm{a}}$ Câmaras Cíveis e a $3 .^{\mathrm{a}}$ Criminal e, ainda, criou 11 cargos de desembargador.

Atualmente, compõe-se o Tribunal de Justiça do Estado de São Paulo de 36 desembargadores. 